\title{
Rapid Determination of Chloramphenicol in Tilapia by ultra-high performance liquid chromatography-mass spectrometry
}

\author{
Shaodong Zeng ${ }^{1,2}$, jianzhi Ye ${ }^{1,2}$, Ling Lin $^{1,2}$, wuhai Chen ${ }^{1,2}$, and Chunliang Yang ${ }^{1,2, *}$ \\ ${ }^{1}$ Agriculture Products Processing Research Institute, Chinese Academy of tropical Agriculture Sciences, Zhanjiang 524001, Guangdong, \\ China \\ ${ }^{2}$ Laboratory of Quality and Safety Risk Assessment on Agro-products Processing(Zhanjiang), Ministry of Agriculture and Rural Affairs \\ of PRC, Zhanjiang 524001, Guangdong, China
}

\begin{abstract}
A rapid method for the determination of residues of chloramphenicol in tilapia by ultra-high performance liquid chromatography-tandem mass spectrometry (UPLC-MS/MS) was established. The samples were extracted with acetonitrile, and separated on a C18 column using methanol-water solution as mobile phase, and then detected under ESI- multiple reaction monitoring mode. The method showed a good linearity for the analysts over the range of $0.1-100 \mu \mathrm{g} / \mathrm{L}$. The detection limits were $0.10 \mu \mathrm{g} / \mathrm{kg}$. The recoveries ranged from $88.6 \%$ to $108 \%$ at spiked concentrations with the relative standard deviations lower than $5 \%$. The results shows that this method has the advantages of easy to operate, fast to perform, with high sensitivity and accuracy, and it is suitable for detection of residues of chloramphenicol in tilapia.
\end{abstract}

\section{INTRODUCTION}

Chloramphenicol (CAP) is an effective broad-spectrum antibiotic active against the main species of pathogenic gram-positive and gram-negative bacteria, as well as against other groups of micro-organisms ${ }^{[1]}$. CAP had been used globally to cure infectious diseases in both humans and animals. The Joint Food and Agriculture Organization/World Health Organization (FAO/WHO) Expert Committee on Food Additives (JECFA) concluded that it was not appropriate to establish an acceptable daily intake (ADI) for CAP because CAP intake may induce aplastic anemia and it exhibits genotoxic effects ${ }^{[2]}$. According to JECFA's recommendation, the use of CAP is restricted in many countries and it is totally banned for use in food-producing animals in China, the EU. Nevertheless, because of its low price, high effectiveness and excellent pharmacokinetic properties, residual CAP has been detected in a variety of imported foods such as fish in china.

Numerous analytical approaches for the determination of residues of CAP have been published. Include gas chromatography ${ }^{[3]}$, gas chromatography-mass spectrometry ${ }^{[4]}$, liquid chromatography-mass spectrometry ${ }^{[5]}$, liquid chromatography-tandem mass spectrometry ${ }^{[6,7]}$, enzyme-linked immunosorbent assay ${ }^{[8]}$. The ability to detect CAP at regulated levels has been dramatically developed by the application of mass spectrometry. With the development of technology, the ultra-high performance liquid chromatography-mass spectrometry(UPLC-MS/MS) has become an important determination and confirmation method ${ }^{[9-13]}$. The aim of this study was to develop a quick UPLC-MS/MS method with high selectivity, sensitivity, easy to operate and fast to perform to detect CAP residues in tilapia samples.

\section{REAGENTS, INSTRUMENTS AND MATERIALS}

Acetonitrile and methanol were chromatographic grade obtained from Spectrum and DIMA respectively. CAP, CAP-D5 were of chromatographic grade (purity $\geq 98 \%$ ) and purchased from Dr. Ehrenstorfer company. While, CAP-D5 was employed as the internal standard (IS) for the quantification of CAP. Their stock solutions were prepared individually at a concentration of $100 \mathrm{mg} / \mathrm{L}$ in acetonitrile, and stored in low-actinic glassware protected from light at $-20^{\circ} \mathrm{C}$ (stable for at least 3 months). All working solutions were prepared by serial dilution of the stock solutions with acetonitrile and stored at $4^{\circ} \mathrm{C}$.

The following instruments were used in this study: ACQMITY UPLCTM-TQ (waters), MS3 Vortex mixter and T25 homogenize(IKA), Milli-QA1 (Millipore), CR22GIII centrifuge (HITACHI), EE120H Ultrasonoscope (Elma).

Tilapia was purchased from aquatic market of Zhanjiang. Once in the laboratory, all of the samples were accuracy weighed, and their head, bone and fat were removed. Fresh Tilapia were separated, homogenised and stored at $-18^{\circ} \mathrm{C}$. The samples with no

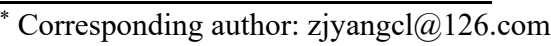


detectable residues of the analytes confirmed were used as negative samples.

\section{SAMPLE PREPARATION}

Tilapia muscles sample 5.00g, D5-CAP, acetonitrile $(20 \mathrm{~mL})$ was added into a $50 \mathrm{~mL}$ centrifuge tube in turn. The mixture was homogenized for $2 \mathrm{~min}$ at $5000 \mathrm{r} / \mathrm{min}$ and shaken periodically for $3 \mathrm{~min}$. Then, the mixture was extraction by ultrasonic for $1 \mathrm{~min}$ followed by centrifuging at $6000 \mathrm{r} / \mathrm{min}$ for $8 \mathrm{~min}$. The supernatant was decanted into a $50 \mathrm{~mL}$ comparison tube.

All solution was collected and heating in a water bath set at $50^{\circ} \mathrm{C}$, the contents were rotoevaporated just to dryness under a reduced pressure. The obtained contents was dissolved with $1.00 \mathrm{~mL}$ methanol-water solution followed by centrifuging at $15000 \mathrm{r} / \mathrm{min}$ for $8 \mathrm{~min}$. The solution was passed through a $0.2 \mu \mathrm{m}$ membrane which was finally subjected to UPLC-MS/MS determination and confirmation.

\section{INSTRUMENT CONDITIONS}

A gradient UPLC system using methanol and water at a flow rate of $0.30 \mathrm{~mL} / \mathrm{min}$, was used to separate CAP on a Waters ACQUITY UPLC BEH C18 column $(50 \times 2.1 \mathrm{~mm}, 1.7 \mu \mathrm{m})$ in Table 1 . The column temperature was $40^{\circ} \mathrm{C}$. The injection volume was $10.0 \mu \mathrm{L}$.

Table 1. UPLC gradient profile for determination of cap

\begin{tabular}{ccccc}
\hline $\begin{array}{c}\text { Time } \\
(\mathbf{m i n})\end{array}$ & $\begin{array}{c}\text { Flow } \\
\text { rate(mL/min) }\end{array}$ & $\begin{array}{c}\text { methanol } \\
\mathbf{( \% )}\end{array}$ & $\begin{array}{c}\text { water } \\
\mathbf{( \% )}\end{array}$ & Curve \\
\hline 0 & 0.30 & 5.0 & 95.0 & \\
0.5 & 0.30 & 5.0 & 95.0 & 6 \\
2.0 & 0.30 & 90.0 & 10.0 & 6 \\
3.0 & 0.30 & 50.0 & 50.0 & 6 \\
4.0 & 0.30 & 5.0 & 95.0 & 1 \\
\hline
\end{tabular}

The analysis was performed using negative ion electrospray interface (ESI-) with multiple reaction monitoring mode. Interface conditions were as follows: capillary voltage was $3.0 \mathrm{kV}$; source temperature was $110^{\circ} \mathrm{C}$; desolvation temperature was $600^{\circ} \mathrm{C}$; the flow rates of cone and desolvation gas (nitrogen) were $150 \mathrm{~L} / \mathrm{h}$ and $600 \mathrm{~L} / \mathrm{h}$, respectively; collision gas was argon; MS/MS parameters were shown in Table 2.

Table 2. MS/MS parameters for determination of CAP

\begin{tabular}{ccccc}
\hline & $\begin{array}{c}\text { Precursor } \\
\text { ions(m/z) }\end{array}$ & $\begin{array}{c}\text { Product } \\
\text { ions(m/z) }\end{array}$ & $\begin{array}{c}\text { Cone } \\
\text { voltage } \\
(\mathbf{V})\end{array}$ & $\begin{array}{c}\text { Collision } \\
(\mathbf{e V})\end{array}$ \\
\hline CAP & 321 & $151.9^{*}$ & 40 & 20 \\
\hline
\end{tabular}

\begin{tabular}{lllll}
\hline & 257 & & 15 \\
CAP-D5 & 326 & 157 & 40 & 15 \\
\hline
\end{tabular}

*Ions for quantification

\section{RESULTS AND DISCUSSION}

\subsection{Optimisation of mobile phase}

Because the kinds of mobile phase have a important roles in UPLC analysis effect, the use of different mobile phase(acetonitrile-water, methanol-water, acetonitrile$5 \mathrm{mmol} / \mathrm{L}$ ammonium acetate solution) were tested. The results shows that when methanol-water used as mobile phase to seperater CAP in ACQUITY UPLC BEH C18 can get a better separation effect, CAP have a higer signal/noise and a better chromatographic peak shape (Fig.1).

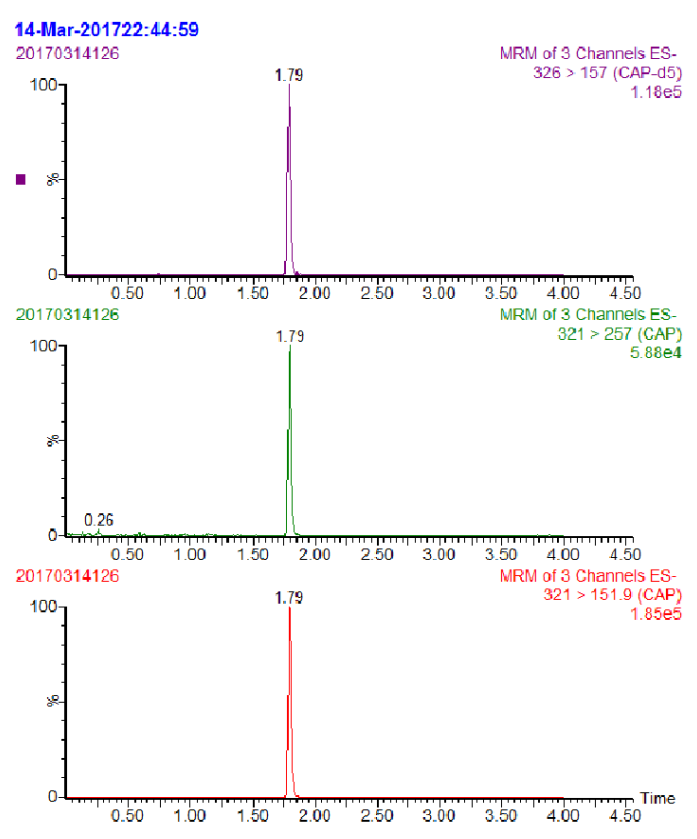

Fig. 1. MRM chromatograms of CAP standards under optimum conditions

(The injection volume was $1 \mu \mathrm{L}$, and the injection concentration was $2.0 \mu \mathrm{g} / \mathrm{L}$ )

\subsection{Linearity}

The calibration curves for CAP were constructed by plotting the peak area (y) versus concentration ( $\mathrm{x}$ ) of each analyte which were expressed by the equation given as: $y=0.8152 x+0.0084$ with a correlation coefficient $\left(r^{2}\right)$ of 0.9994 . The calibration curves were generated daily from the peak area responses of standards with concentrations ranging from 0.1 to $100 \mu \mathrm{g} / \mathrm{L}$. 


\subsection{Limit of detection}

The negative samples were spiked with the standard solution, then pretreated and analyzed following the method described above. The LOD for CAP were obtained from the analysis of the negative samples spiking with mixed standard solution. The LOD based on three times the signal to noise ratio were $0.10 \mu \mathrm{g} / \mathrm{kg}$.

\subsection{Accuracy of methods}

For estimation of accuracy, negative samples were added with CAP standard solution. Six replicate tests, at each of the three fortification levels, were analysed. The recovery of the method was determined using tilapia samples fortified at $0.1 、 0.5 、 2.0 、 5.0 \mu \mathrm{g} / \mathrm{kg}$. Mean recovery $(n=6)$ of the analytes, determined in three separate assays shown in Table 3 was between $88.6 \%$ to $108 \%$ and the relative standard deviations lower than $5 \%$.

Table 3. Recoveries and relative standard deviations(RSD) of CAP in samples $(n=6)$

\begin{tabular}{cccc}
$\begin{array}{c}\text { Spiked } \\
\begin{array}{c}\text { concentrations } \\
(\mu \mathrm{g} / \mathrm{kg})\end{array}\end{array}$ & $\begin{array}{c}\text { Mean } \\
\text { measured } \\
\text { concentrations } \\
(\mu \mathrm{g} / \mathrm{kg})\end{array}$ & $\begin{array}{c}\text { Mean } \\
\text { recovery } \\
(\%)\end{array}$ & $\begin{array}{c}\text { RSD } \\
(\%)\end{array}$ \\
\hline 0.1 & 0.108 & 108 & 4.3 \\
0.5 & 0.517 & 103 & 2.6 \\
2.0 & 1.87 & 93.5 & 3.3 \\
5.0 & 4.43 & 88.6 & 3.5 \\
\hline
\end{tabular}

\section{CONCLUSIONS}

In this study, a rapid method was developed for determination of CAP in tilapia. The results shows that this method has the advantages of easy to operate, fast to perform, with high sensitivity and accuracy, and it is suitable for detection of residues of chloramphenicol in tilapia.

\section{ACKNOWLEGEMENTS}

This word was financially supported by Central Public-interest Scientific Institution Basal Research Fund for Chinese Academy of Tropical Agricultural Sciences (No.1630122017020), and the National Program for Quality and Safety Risk Assessment of Agricultural Products of China (GJFP2018011、GJFP2018004).

\section{REFERENCES}

1. A.D. Cooper, J.A. Tarbin, W.H.H. Farrington, G. Shearer, Aspects of extraction, spiking and distribution in the determination of incurred residues of chloramphenicol in animal tissues. Food Additves \& Contaminants, 15, 637-644 (1998)

2. R.L. Epstein, International validation study for the determination of chloramphenicol in bovine muscle. Journal of AOAC International, 77, 570-576 (1994)

3. S. Borner, H. Fry, G. Balizs, R. Kroker, Confirmation of chloramphenicol residues in egg by gas chromatography/high-resolution mass spectrometry and comparison of quantitation with gas chromatography-Electron capture detection. Journal of AOAC International,78,1153-1160 (1995)

4. A. Gantverg, I. Shishani, M. Hoffman, Determination of chloramphenicol in animal tissues and urine liquid chromatography-tandem mass spectrometry versus gas chromatography-mass spectrometry. Analytica Chemica Acta, 483,125-135 (2003)

5. K. Fujita, H. Ito, M. Nakamura, M. Watai, Determination of chloramphenicol residues in Bee pollen by liquid chromatography/tandem mass spectrometry. Journal of AOAC International, 91, 1103-1109 (2008)

6. S. R. Rocha Siqueira, J. Luiz Donato, G. de Nucci, F.G.R. Reyes, A highthroughput method for determining chloramphenicol residues in poultry, egg, shrimp, fish, swine and bovine using LC-ESI-MS/MS. Journal of Separation Science, 32, 4012-4019 (2009)

7. R.W. Fedeniuk, M. Mizuno, C. Neiser, C. O’Byrne, Development of LC-MS/MS methodology for the detection/determination and confirmation of chloramphenicol, chloramphenicol 3-O-b-Dglucuronide, florfenicol,florfenicol amine and thiamphenicol residues in bovine, equine and porcine liver. Journal of Chromatography B, 991, 68-78 (2015)

8. A. Posyniak, J. Zmudzki, J. Niedzielska, Evaluation of sample preparation for control of chloramphenicol residues in porcine tissues by enzyme-linked immunosorbent assay and liquid chromatography. Analytica Chemica Acta, 483,307-311 (2003)

9. W.L. Liu, R.J. LEE, M.R. LEE. Supercritical fluid extraction in situ derivatization for simultaneous determination of chloramphenicol, florfenicol and thiamphenicol in shrimp. Food Chemistry, 121: 797-802 (2003)

10. J.R. Shakila, R. Saravanakumar, S. Vyla, et al. An improved microbial assay for detection of chloramphenicol residues in shrimp tissues. Innovative Food Science and Emerging Technologies, 8: 515-518(2007)

11. Y.B. Lu, T.L. Zheng, X. He. Rapid determination of chloramphenicol in soft-shelled turtle tissues using on-line MSPD-HPLC-MS/MS. Food Chemistry, 
134: 533-539(2012)

12. K. Li, L. Liu, C. Xu, X. Chu. Rapid determination of chloramphenicol residues in aquaculture tissues by immunochromatographic assay. Analytical Sciences, 23 (11) :1281-1284(2007)

13. E. Gikas, P. Kormali, D. Tsipi, A. Tsarbopoulos. Development of a rapid and sensitive SPE-LC-ESI MS/MS method for the determination of chloramphenicol in seafood. Journal of Agricultural \& Food Chemistry, 52 (5) :1025-30(2004) 